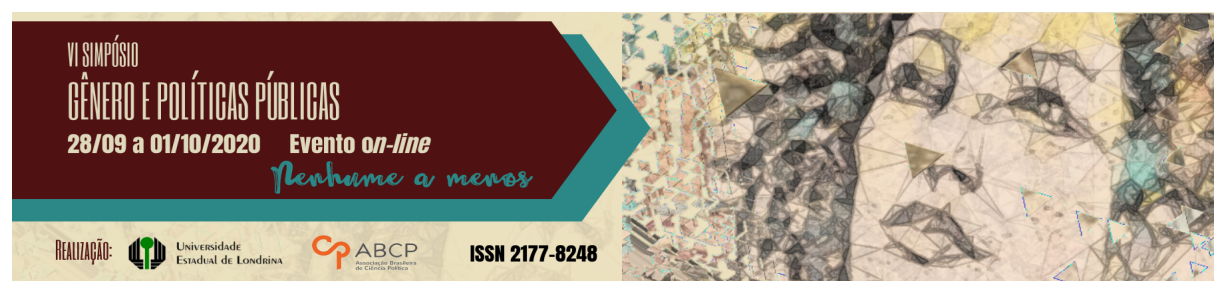

\title{
Narrativas de mulheres sírias: refúgio e humanitarismo ${ }^{1}$
}

\author{
Mirian Alves de Souza²
}

\begin{abstract}
Resumo
Este artigo é baseado em trabalho de campo etnográfico com mulheres refugiadas do Conflito sírio no Rio de Janeiro e São Paulo de 2015 a 2018. O texto discute narrativas de mulheres refugiadas que desafiam discursos nos quais elas são apresentadas como eternamente vulneráveis ou oprimidas pela "cultura", reconhecendo sua agência e descrevendo outras dinâmicas de poder interseccional. Este texto contribui para o debate antropológico sobre refugiados do Oriente Médio a partir de uma crítica à retórica humanitária sobre os corpos das mulheres.
\end{abstract}

Palavras-chave: Mulheres refugiadas; Conflito sírio; humanitarismo.

\section{Narratives of Syrian women: refuge and humanitarianism}

\begin{abstract}
This article is based on ethnographic fieldwork among female refugees of the Syrian conflict in Rio de Janeiro and São Paulo from 2015 to 2018. It presents and discusses female refugee narratives that challenge the image of refugee women as eternally vulnerable or oppressed by "culture", recognizing their agency and describing other intersectional power dynamics. Thus, this article contributes to the anthropological debate on Middle Eastern women and refugees though a critique of the humanitarian rhetoric on women's bodies.
\end{abstract}

\footnotetext{
1 Agradeço às organizadoras do GT pela interlocução e, especialmente, por seus comentários.

2 mirian.uff@gmail.com, doutora e mestre em Antropologia PPGA/UFF, professora do Departamento de Antropologia e do Programa de Pós-graduação em Justiça e Segurança da Universidade Federal Fluminense PPGJS/UFF. Pesquisadora do Núcleo de Estudos do Oriente Médio NEOM e INEAC-INCT/UFF.
}

GT 12 - Gênero, refúgio e migrações 
Key-words: Female refugee; Syrian conflict; humanitarian rhetoric.

\section{Introdução}

Em Imposing Aid (1986), Barbara Harrell-Bond considerou as agências humanitárias, seus apoiadores internacionais, governos locais e pessoas anfitriãs em um momento no qual o trabalho humanitário não estava acostumado a ser submetido a avaliações etnográficas. HarrellBond descreveu como as boas intenções deram lugar à irritação e até mesmo hostilidade quando trabalhadores humanitários vivenciaram experiências de desconforto, fracasso e traição de confiança de pessoas que eles pensavam que deveriam ser gratas, mas que não eram. Para Harrell-Bond $(1986,2002)$ aqueles que trabalhavam em tais condições eram vítimas junto com os refugiados e as agências precisavam estar cientes de suas prováveis respostas ao estabelecer programas de ajuda. Colson (2011, p. 158) argumenta que Imposing Aid despertou a hostilidade de muitos que se sentiram sob ataque quando viram seu trabalho exposto ao escrutínio público.

A partir de sua pesquisa com refugiados de Uganda, no Sul do Sudão, Harrell-Bond (1986; 2002) desafia uma narrativa homogênea sobre o refúgio, mostrando que seus interlocutores eram diferentes de muitas maneiras (idade, educação, gênero, classe social e assim por diante). Em seu trabalho, no contexto de um campo de refugiados, ela considerou a interação de uma infinidade de atores. Harrell-Bond articulou a pesquisa com refugiados ao campo do humanitarismo e questionou a racionalidade e validade da ajuda humanitária. HarrellBond concordava que os ugandenses entrando no Sudão precisavam de vários tipos de assistência humanitária, incluindo o serviço de fornecimento de alimentos e medicamentos. Mas ela trouxe para o trabalho das agências humanitárias o mesmo tipo de escrutínio já usado no estudo de projetos de desenvolvimento (HARRELL-BOND, 1986).

Atualmente, as críticas de Imposing Aid (1986) continuam pertinentes e reafirmam o impacto deletério dos campos de refugiados 
e de certas práticas humanitárias (por exemplo, AGIER, 2011; HAMID, 2012; SCHIOCCHET, 2017). Nessa perspectiva crítica, situa-se o trabalho de Sonia Hamid (2012; 2019). Pesquisando um programa de "integração" para refugiados palestinos reassentados na cidade de Mogi das Cruzes, em São Paulo, Hamid problematiza o uso da categoria "cultura", frequentemente mobilizada pelos atores que atuavam na gestão do programa. Hamid (2019, p. 115) argumenta que "a 'cultura' era tratada de forma totalizante, explicativa dos comportamentos dos sujeitos assistidos, sendo também acionada, em geral, de modo acusatório, na medida em que era mencionada para apontar elementos indesejáveis que precisariam, apesar da dificuldade, serem transformados". Apesar da diversidade de práticas e comportamentos entre os refugiados, Hamid descreveu que os agentes humanitários mobilizavam um conceito predefinido de cultura, ignorando os casos que desafiavam sua visão pré-determinada, encarando-os como uma exceção (HAMID, 2019, p. 129).

Pesquisas empíricas mais recentes (LOKOT, 2018; HAMID, 2019) questionam a ênfase nas categorias "tradição" e "cultura", acionadas por agentes humanitários, que não descrevem ou explicam o que "cultura" ou "tradicional" significam. Michelle Lokot argumenta que, nas narrativas humanitárias, as famílias sírias refugiadas na Jordânia são classificadas como "tradicionais", embora sem explicação do que "tradicional" realmente signifique além da divisão aparentemente típica de papéis para mulheres e homens (LOKOT, 2018, p. 02). O enquadramento binário, liberal ou conservador e tradicional ou moderno, oculta nuances muito mais complexas. Afirmações sobre as mulheres refugiadas devem ser contextualizadas, considerando os elementos históricos, sociais, culturais e políticos que moldam suas identidades. Não existe uma imagem visual pré-determinada do refúgio, assim como da "mulher refugiada".

Liisa Malkki (1995), a partir de sua pesquisa com refugiados hutus na Tanzânia, apresenta uma crítica muito contundente a narrativas sobre os refugiados que ignoram o conflito e o contexto de perseguição e opressão que dão origem ao deslocamento. Estas 
narrativas obscurecem uma dimensão central no refúgio para privilegiar o corpo do refugiado e sua cultura: "É impressionante a frequência com que a abundante literatura reivindicando os refugiados como objeto de estudo localiza 'o problema' não primeiro na opressão política ou violência que produz deslocamentos territoriais massivos de pessoas, mas dentro dos corpos e mentes das pessoas classificadas como refugiadas" (MALKKI, 1995, p. 8).

A centralidade do corpo das mulheres em discursos acadêmicos e humanitários tem sido problematizada na perspectiva dos estudos de gênero no Oriente Médio (ABU-LUGHOD, 1996, MAHMOOD, 2005; RABO, 1996; 2008). As mulheres e/ou a família foram e ainda são usadas para representar simbolicamente o progresso e a tradição cultural das sociedades em toda a região (RABO, 1996, p. 156). A produção antropológica contemporânea tem se expandido no sentido de oferecer uma visão mais nuançada das mulheres médio-orientais, questionando e descontruindo discursos reducionistas (SA'AR, 2001; MAHMOOD, 2005; CHAGAS, 2011; LOKOT, 2018; HAMID, 2019).

A discussão sobre agência feminina tem contribuído para essa discussão. A etnografia de Saba Mahmood (2005) nas mesquitas do Cairo, em um movimento conservador de mulheres, deu lugar a uma nova concepção de agência. Mahmood desenvolveu um conceito de agência devota, que amplia a capacidade de compreensão das mulheres cujo sentido de self, aspirações, projetos e desejos, incluindo o de submissão a uma autoridade reconhecida, foram configurados no seio de tradições não liberais. Mahmood defende uma separação entre a noção de agência e a de resistência como um passo fundamental para se pensar as formas de vontade e política que não se adequam às normas seculares e liberais feministas, (MAHMOOD, 2005, p. 121) incluindo o "feminismo de estado sírio".

Este artigo considera essa bibliografia para pensar a etnografia sobre mulheres afetadas pelo conflito sírio no Brasil. $\mathrm{O}$ artigo pretende contribuir para esse campo de pesquisas sobre refúgio e mulheres médio-orientais. Existem poucos trabalhos com foco em mulheres 
refugiadas da Síria no Brasil e que abordem suas relações com o trabalho humanitário. Neste texto, apresento uma crítica a certos discursos humanitários, que focalizavam o corpo das mulheres. O decote e o hijab são mobilizados nestes discursos para explicar comportamentos e questionar vulnerabilidades. $\mathrm{O}$ artigo explora a importância de uma análise que considere diferentes pertencimentos e reconheça a agência das mulheres, definidas como conservadoras e não modernas.

\section{Conflito sírio}

Desde o começo do conflito sírio, em 2011, estima-se que 6,7 milhões de pessoas foram deslocadas internamente na Síria, 5,6 milhões deixaram o país, e 13,5 milhões precisam de ajuda humanitária. Antes do conflito, a população da Síria era estimada em 22 milhões de pessoas. Atualmente, a metade dessa população foi deslocada de suas casas. A Síria é o país que mais produz refugiados no mundo (ACNUR, 2018). Sobre a guerra da Síria, Pinto (2017) expõe as complexidades do conflito, frequentemente abordado em uma perspectiva sectária, criticando esse enquadramento e mostrando como o regime do presidente Bashar alAsad usou da violência para forjar um conflito sectário, a partir de tensões pré-existentes.

A maioria dos refugiados do conflito está em países vizinhos, de fronteira, os quais abrigam $90 \%$ do total de deslocados. Os países que mais receberam refugiados sírios são Turquia, Líbano e Jordânia (ACNUR, 2018). No Brasil, entre 2011 e 2018, 3.326 cidadãos sírios foram reconhecidos como refugiados, segundo dados oficiais do Comitê Nacional para refugiados (CONARE 2019), que administra o refúgio no Brasil. A entrada de pessoas afetadas pelo conflito sírio no Brasil foi facilitada, por "razões humanitárias", através da flexibilização das exigências para a concessão de visto em embaixadas e consulados brasileiros. 


\section{Metodologia}

O trabalho de campo que informa este artigo foi conduzido de outubro de 2015 a setembro de 2018, no Rio de Janeiro e em São Paulo, Brasil $^{3}$. No Rio de Janeiro, a pesquisa adotou uma metodologia baseada na observação participante. O trabalho foi desenvolvido com imersão, tornei-me, por exemplo, aluna de meus interlocutores, professores de árabe. Em São Paulo, realizei entrevistas mais estruturadas, que tinham objetivos mais específicos.

A etnografia privilegiou a descrição do processo de acolhimento de pessoas afetadas pelo conflito sírio, considerando cidadãos sírios e de outras nacionalidades, como palestinos e libaneses. Esses refugiados viviam em áreas urbanas do Rio de Janeiro e São Paulo e possuíam uma grande diversidade socioeconômica. Eles tinham entre 18-65 anos e eram em sua maioria de Damasco, Alepo, Dayr al-Zor, Daraa, Raqqah e Homs na Síria.

As entrevistas e aulas particulares foram conduzidas em minha casa, na residência de algumas interlocutoras, em cafés, restaurantes e na Fundação Casa de Rui Barbosa FCRB. Feiras de comida, organizações humanitárias e confessionais, eventos culturais e acadêmicos, como palestras e peças teatrais também foram espaços para $o$ desenvolvimento do trabalho de campo.

\section{O decote de Randa}

Na programação do I Curso de Verão sobre refúgio da Fundação Casa de Rui Barbosa, em dezembro de 2015, houve uma visita à Caritas Arquidiocesana, no Rio de Janeiro, na qual os participantes conheceram Randa4. Ela era jovem e apesar de estar há poucos meses no Brasil, falou em português, utilizando-se do inglês para formulações discursivas mais complexas. Ela apresentou-se para o público de participantes do

\footnotetext{
3 A pesquisa foi financiada com bolsa de Doutor da Fundação Casa de Rui Barbosa.

4 Todos os nomes de interlocutores utilizados correspondem a pseudônimos
} 
Curso como síria, solicitante de refúgio no Brasil, e abordou aspectos de sua vida. Ela contou que trabalhou como operadora de telemarketing na Turquia para o pagamento de sua passagem de avião para o Brasil, e explorou o seu interesse em estudar em uma universidade brasileira, sua curiosidade por novas culturas e pela língua portuguesa.

Randa vivia em Damasco com sua mãe, onde nasceu na década de 1990. Sua família era síria, damascena, e muçulmana sunita, mas, como seus pais, ela não era uma muçulmana praticante. Randa estudou em uma escola bilíngue em Damasco, motivo pelo qual falava inglês fluentemente, fazia aulas de pintura no Russian Cultural Center, e frequentava outros espaços sociais de classe média alta na Síria. Na última década, no entanto, sua família vivenciou um acentuado declínio econômico, agravado pela eclosão do conflito em 2011. Quando Randa chegou ao Brasil, em 2015, não recebia nenhum tipo de apoio financeiro de parentes, e com o dinheiro que ganhou trabalhando, como atendente de bar em Beirute e operadora de telemarketing em Istambul, se estabeleceu no Brasil nos primeiros meses. Quando trouxe sua mãe para o Rio de Janeiro, ela começou a trabalhar como professora de inglês e, eventualmente, de árabe. Para sustentar a si e sua mãe, Randa dependia exclusivamente de seu trabalho.

Ao fim da visita à Caritas, os participantes do Curso se dividiram em pequenos grupos em direção à saída da organização. Em um desses grupos, Maria, que possuía uma posição de trabalho relevante, e sênior, na estrutura de uma organização humanitária internacional, questionou abertamente a origem nacional de Randa, afirmando: "Tenho certeza que ela é palestina se fingindo de síria para conseguir refúgio. Agora todo mundo é sírio. Com esse decote, ela não é síria" (Trabalho de campo, dezembro de 2015). O discurso de Maria possui dimensões discutidas pela literatura antropológica sobre o tema do refúgio, como a desconfiança em relação ao refugiado e uma determinada construção visual da "vítima" (HARRELL-BOND, 1986; 2002; FASSIN, 2010; LOKOT, 2018; HAMID, 2019). 
Quando aconteceu a visita à Caritas, o conflito sírio alcançava grande visibilidade pública. Em setembro de 2015, fotografias de uma criança síria afogada em uma praia perto da cidade de Bodrum, na Turquia, repercutiram globalmente. A fotojornalista turca, Nilüfer Demir, fez uma série de fotos do menino Alan Kurdi, que morreu ao tentar atravessar o mar mediterrâneo em direção à Europa com sua família. Apenas o pai sobreviveu e as fotografias do pequeno Alan vestido com uma camiseta vermelha e calça azul chamaram a atenção para o conflito (ADLER-NISSEN; ANDERSEN; HANSEN, 2019, p. 75). As fotografias contribuíram para que o conflito sírio e a crise humanitária que ele produz se tornassem amplamente conhecidos no Brasil, embora o número de refugiados nesse momento já chegasse a quatro milhões de pessoas.

O reconhecimento do conflito sírio como uma crise humanitária, face a repercussão das fotografias do menino Alan Kurdi, relaciona-se à ideia de Didier Fassin de que a exposição do corpo sofredor é o que restou como último recurso simbólico audível em situações de extrema exclusão social ou legal (FASSIN, 2016, p. 46). As fotografias do menino Alan Kurdi contribuíram para que o conflito sírio deixasse de ser uma guerra distante e passasse a ser reconhecido como uma crise humanitária perante um grande público no Brasil. Em sua pesquisa com refugiados palestinos do conflito sírio em São Paulo, Helena Manfrinato analisa a mobilização e o apoio que os refugiados receberam da sociedade civil diante da comoção pública produzida pelas fotografias do menino: "Seu corpo sem vida diante de uma imensidão inóspita de água, completamente vulnerável, acendeu a comoção e indignação das pessoas, que gostariam de reparar aquilo, e reverter a sensação de que o socorro vinha tarde demais". (MANFRINATO, 2016, p. 428).

O comentário da trabalhadora humanitária evocou o contexto de visibilidade do conflito sírio, que se relaciona à comoção pública produzida pelas fotografias. Nesse contexto, o trânsito de nacionais da Síria era classificado como de caráter humanitário, permitindo a categorização dos sírios como refugiados. Ao dizer que "agora, todo 
mundo é sírio", Maria pressupôs que Randa falsamente se associava a uma identidade amplamente reconhecida como de vítima. Indiscutivelmente o menino Alan era uma vítima. Randa, no entanto, não se enquadrava em uma definição de vítima, comum aos trabalhadores humanitários.

Harrell-Bond argumenta que a justificativa externa para financiar a estrutura institucional e administrativa criada para distribuir ajuda depende de maneiras específicas de retratar os refugiados como desamparados e desesperadamente necessitando de assistência internacional. Essa imagem reforça a visão de que pessoas de fora são necessárias para ajudá-los. Também condiciona o comportamento de quem ajuda, cujos interesses servem à patologização, medicalização e rotulagem do refugiado como desamparado e vulnerável (HARRELLBOND, 2002, p. 57). Não correspondendo a uma certa imagem de vítima, Randa não era reconhecida como síria. O conceito de "vulnerabilidade" é frequentemente importante na definição de quem recebe os serviços e quem não recebe (AGIER, 2011, p. 213) e isso é particularmente verdadeiro para o caso da Síria.

A enorme variedade de práticas e comportamentos entre as mulheres sírias ou palestinas não permite enquadramentos totalizantes. Randa questionou a ideia segundo a qual uma mulher síria não usa decote: "Ela [Maria] tem uma visão muito limitada, porque tudo depende. Tem os liberais e tem os conservadores, tanto do lado dos sírios quanto dos palestinos" (Entrevista em junho de 2017). O enquadramento binário, liberal ou conservador e tradicional ou moderno, oculta nuances muito mais complexas. Afirmações sobre as mulheres sírias ou palestinas exigem contextualização dos elementos históricos, sociais, culturais e políticos que moldam suas identidades.

\section{O hijab de Samia}

Samia nasceu em Damasco na década de 1980, em um campo não oficial de refugiados palestinos. Ela cresceu no subúrbio da cidade 
e estudou na Universidade de Damasco, onde conheceu seu marido. Depois de alguns anos de casamento, Samia deixou a Síria com Khaled e o pequeno filho do casal. Em 2015, eles chegaram ao Brasil, depois de viverem na Jordânia e terem seus pedidos de visto negados por diversos países.

Conheci Samia e sua família em 2016, no Rio de Janeiro, e, em 2017, nos reencontramos em São Paulo. Samia sugeriu que participássemos de um evento para refugiados, promovido por diversas organizações humanitárias. Samia compareceu ao evento em resposta ao convite de amigos que ela fez na Mesquita que frequentava em São Paulo. Eles trabalhavam como voluntários em uma associação islâmica vinculada à Mesquita.

Samia contou que frequentava apenas episodicamente a mesquita em Damasco. Quando deixaram a Síria, depois do conflito, ela e seu marido começaram a ir com regularidade à mesquita em Amã e, depois, em São Paulo. Samia disse que, diferente de Khaled, não tinha o hábito de ir à mesquita ou rezar diariamente em sua casa. Porém, com o início do conflito sírio, e fora da Síria, passou a se sentir conectada à religião: "passar pelo o que o profeta Mohamed passou, me conectou ao islä" (Samia, entrevista, junho de 2017). A experiência da migração forçada (hijra, quando o profeta deixa Meca em direção à Medina), em decorrência do conflito sírio, aproximou Samia da religião e das comunidades muçulmanas em Amã e em São Paulo. As redes de relações ligadas à mesquita foram importantes para o estabelecimento de Samia e Khaled nas duas cidades.

Realizado em um amplo espaço público, o evento em São Paulo tinha um caráter informativo sobre o tema do refúgio e dos direitos humanos e contava com voluntários e trabalhadores humanitários do ACNUR, da Caritas Arquidiocesana de São Paulo, e das ONGs I know my Rights IKMR e Instituto de Reintegração do Refugiado ADUS, entre outras organizações. Os trabalhadores humanitários informavam nas diversas tendas distribuídas no espaço do evento sobre os direitos dos refugiados, de mulheres e crianças. Em uma dessas tendas, conheci 
Joana, que trabalhava formalmente em uma das organizações presentes no evento, e duas voluntárias. Joana ocupava uma posição de liderança em sua organização, tinha experiência internacional de trabalho humanitário, curso superior completo e pós-graduação.

Em uma das barracas de alimentação do evento, entrevistei Joana e as voluntárias, enquanto tomávamos café. Joana começou a entrevista me explicando sobre o seu trabalho e o papel de sua organização no evento. Depois, passou a falar sobre as "mulheres sírias" de forma mais específica, a partir da experiência de Samia. Joana e uma das voluntárias conheceram Samia na ocasião de um outro evento realizado por suas organizações.

Joana descreveu Samia como uma mulher "tradicional" e afirmou que sua "cultura tradicional" era um "problema" para a "integração" dela à sociedade brasileira. Ela repetiu isso por diversas vezes, enquanto as voluntárias balançavam suas cabeças demonstrando aprovação. Diante da pergunta, o que significa "tradicional"? Joana respondeu: "Samia parece do tempo da minha avó, não como minha avó, porque a minha avó trabalhava. (...) Ela é muito tradicional" (Entrevista em junho de 2017). As voluntárias realçaram que Samia era até mesmo mais "conservadora" e "religiosa" do que as outras mulheres muçulmanas presentes no evento e que vestiam calças jeans justas ao corpo, blusas de tecido mais fino com mangas sete oitavos e hijabs coloridos. Distintamente, Samia vestia uma saia longa e folgada, blusa de gola rolê de manga longa, colete comprido, touca e hijab em uma combinação monocromática com diversas tonalidades de preto e cinza. Joana seguiu me explicando que a "cultura muçulmana" e a "cultura árabe" não permitiriam às mulheres "terem liberdade (...). Eles são muito tradicionais" (Entrevista em junho de 2017).

Embora não conhecesse Khaled, Joana atribuía ao marido de Samia a razão pela qual ela não se interessou por uma oportunidade de trabalho oferecida. Na ocasião em que se conheceram, Joana ofereceu à Samia sua colaboração para que encontrasse uma posição de trabalho no contexto de um programa de emprego. Elas conversaram 
pessoalmente e, depois, trocaram mensagens através do aplicativo WhatsApp. Joana argumentou que, a princípio, Samia estava interessada na proposta de emprego, pois enviou o seu currículo. Alguns dias depois, no entanto, não respondeu às sucessivas mensagens enviadas pela voluntária da organização na qual Joana trabalhava e, por fim, respondeu que não estava interessada. Para Joana e a voluntária, o marido de Samia a levou a desistir de concorrer à vaga de emprego. Essa suposição baseava-se na ideia de que a família de Samia era "muito tradicional". Joana seguiu sua fala, sempre com a concordância gestual das voluntárias, reafirmando a "cultura tradicional" de Samia e das "mulheres muçulmanas", que "usam véu e ficam em casa".

Perguntei para Samia sobre a proposta de trabalho que lhe foi feita por Joana. A vaga de auxiliar administrativo, para uma jornada de trabalho de 44 horas semanais, correspondia ao valor do piso nacional para a categoria profissional e o processo de seleção envolveria a análise de currículo e uma entrevista. Samia não participou da seleção e justificou seu desinteresse. Samia mencionou diversos elementos para sua decisão, porém os mais significativos em sua perspectiva tinham a ver com o seu filho de 3 anos. Um argumento era o longo tempo que ficaria afastada dele. Ela me explicou que, aceitando a proposta de emprego, estaria ausente de sua casa por quase 13 horas, considerando o tempo da jornada de trabalho, de 9 horas, e do deslocamento diário (casa-trabalho-casa), de 2 horas e 30 minutos. Outro argumento era que o valor do salário, considerando o seu orçamento familiar, não permitiria pagar uma mensalidade pré-escolar. Samia já sabia que não conseguiria uma vaga na rede pública de creche. Ao procurar o ensino pré-escolar assim que chegou em São Paulo, ela foi informada de que a demanda de vagas na sua região de moradia era muito alta e não conseguiria realizar a matrícula naquele mesmo ano.

\section{Agência e as "mulheres que usam véu e ficam em casa"}


A imagem da mulher síria sem decote, de hijab e oprimida por sua "cultura tradicional" corresponde a um estereótipo que, como o texto mostrou, foi reproduzido por trabalhadoras humanitárias, que ocupavam posições seniores na estrutura burocrática de suas organizações. Como Michael Herzfeld argumenta, “os estereótipos são produzidos no topo" (1992, p. 71). Embora o uso e difusão de estereótipos sejam frequentemente atribuídos ao discurso popular, Herzfeld (1992) mostra como eles são mobilizados pelos estados e atores burocráticos.

O projeto modernizante do partido Ba'ath, o único a governar a Síria desde a década de 1960, também mobilizou o estereótipo da mulher síria de hijab e oprimida por sua cultura patriarcal. Segundo Annika Rabo, iniciativas, como os grupos de estudos para mulheres adultas, organizados pelo Sindicato das Mulheres, controlado pelo Ba'ath, são instrumentos importantes para ensinar as mulheres a "se livrarem das atitudes tradicionais" (RABO, 1996, p. 160). No discurso oficial do partido Ba'ath, a sociedade deve se "modernizar" e a mulher têm um papel importante nesse processo. A ideologia do partido enfatizou a similaridade inerente entre homens e mulheres através do sufrágio, políticas educacionais e oportunidades de emprego. A retórica oficial defende que homens e mulheres, lado a lado, devem construir uma nação nova e desenvolvida para o bem de todos (RABO, 1996, p. 157). No entanto, como argumenta Deniz Kandiyoti, para nacionalistas no Oriente Médio que criaram um feminismo de estado, a reclusão das mulheres teve de ser abolida, porque as mulheres reclusas eram "um recurso nacional desperdiçado" e não porque tinham direitos iguais (KANDIYOTI, 1991, p. 10).

Nos discursos do feminismo de estado e das trabalhadoras humanitárias, o véu islâmico é um símbolo da opressão feminina e o trabalho, por sua vez, é um símbolo de modernidade e indicador da liberdade das mulheres. Ambos discursos não reconhecem a agência feminina (MAHMOOD, 2005) em mulheres que "usam véu e ficam em casa", para usar a frase de Joana para se referir à Samia. 
A classe social, assim como o valor atribuído ao trabalho (SALAMANDRA, 2004; HIJAB, 1988), tem um papel importante no que se refere ao exercício de uma atividade remunerada. Randa trabalhou como atendente de bar, operadora de telemarketing e professora. Com o dinheiro de seu trabalho, ela sustentava sua família no Brasil. A mãe de Randa, entretanto, nunca trabalhou. Ela nasceu no seio de uma família abastada e, mesmo diante do declínio econômico familiar, recusou-se a fazê-lo. Para Randa, sua mãe não aceitava trabalhar, porque tinha "mentalidade de elite". A mãe de Randa também usava decote, de modo que o fato dela não trabalhar não poderia ser facilmente atribuído à sua "cultura tradicional".

Nadia Hijab $(1988,2001)$ mostra que a classe social e as condições de trabalho devem ser consideradas, antes de se atribuir exclusivamente à cultura a razão pela baixa participação de mulheres sírias no mercado de trabalho. Hijab (1988) argumenta que as mulheres de níveis socioeconômicos médios eram bastante privilegiadas. Elas trabalhavam no setor público, que, no mundo árabe, oferece as "carreiras mais valorizadas e respeitáveis para as mulheres, tanto em termos de segurança no emprego quanto porque a natureza do trabalho não é manual" (1988, p. 88). Nesse caso, as mulheres estavam ansiosas por aproveitar a oportunidade de trabalhar para satisfazer as necessidades econômicas. Esse não era necessariamente o caso de mulheres de origens socioeconômicas mais baixas (HIJAB, 1988, p. 88-9).

O motivo pelo qual Samia não quis participar do processo seletivo para a vaga sugerida por Joana tinha a ver com um conjunto de fatores, como a baixa remuneração e a ausência de vaga em uma creche para seu filho. A abordagem de "culpar o Islã" por manter as mulheres fora do mercado de trabalho ignora o fato de que muitos problemas enfrentados por essas trabalhadoras são, em geral, compartilhados em todo o mundo. Nesse sentido, não é possível atribuir ao peso da tradição a não inserção de Samia no mercado de trabalho paulistano. De outra forma, entretanto, ela participava desse mercado. 
Nadia Hijab (2001, p. 41) desafia a suposição comum de que as mulheres no mundo árabe não trabalham. Hijab argumenta que o trabalho está fortemente localizado em áreas onde é "invisível", principalmente na agricultura, em empresas familiares, na economia doméstica e em outros locais da economia informal. (HIJAB, 1988, p. 12; QUATAERT, 1991, p. 163). A invisibilidade do uso da força de trabalho das mulheres também aparece nos discursos familiares. Mary Chamie (1985, p. 99) observou, ao citar uma pesquisa sobre a participação das mulheres na força de trabalho na Síria, que ao perguntar inicialmente aos homens se suas esposas trabalhavam, uma grande proporção respondeu que não. Quando a pergunta foi reformulada para "Se sua esposa não o ajudasse no seu trabalho, você seria forçado a contratar um substituto para ela?", a esmagadora maioria respondeu que sim (1985, p.99). Este é o caso de Samia que atuava como assistente de seu marido, dividindo seu tempo entre esse trabalho e os cuidados com a família.

Samia tinha planos profissionais e reclamou que, em Damasco, não havia perspectiva de trabalho. Ela desejava migrar para um país do Norte Global, como o Canadá, onde ela poderia encontrar condições para construir uma carreira. Samia se dizia diferente das mulheres da família de seu marido, membro da elite damascena, que quando faziam universidade ou trabalhavam, era apenas como uma forma de atrair maridos. Christa Salamandra (2004) argumenta que a maioria dos empregos abertos às mulheres em Damasco, por mais prestigiado que seja, não paga o suficiente para permitir que as mulheres se tornem economicamente auto-suficientes. Os empregos são vistos como medidas temporárias no caminho para o casamento ou posteriormente como renda suplementar. "Para as jovens solteiras, os empregos são principalmente um local de exibição, cujo objetivo final é garantir um futuro de sucesso na esfera privada, e não na pública" (SALAMANDRA, 2004, p. 52).

Em sua família, de refugiados palestinos, Samia mencionou um processo diferente. A maioria das mulheres desejava passar mais tempo com seus filhos, desenvolver um sentimento mais profundo de cuidado e "conectividade" (JOSEPH, 1994, p. 55) com suas famílias. Entretanto, 
mesmo priorizando a vida familiar e doméstica, viam-se obrigadas a trabalhar fora de casa por longas horas, pois desempenhavam um papel fundamental na economia familiar. Para sua prima, que pretendia se casar muito em breve, o trabalho formal era concebido como um estorvo. Ela estava ansiosa em abandonar o trabalho mal remunerado como assistente de cozinha em um restaurante, depois do casamento. Esse trabalho também era muito pesado e, por sua história familiar, ela sabia o quanto seria exaustivo cuidar da casa, da família e ainda ter um trabalho formal. O desejo de ficar em casa não deve ser ignorado ou reduzido a uma questão de segregação das mulheres.

A pesquisa indica que é um erro considerar que as mulheres das classes populares são mais segregadas do que as mulheres urbanas e elitizadas. Para Samia, as mulheres solteiras eram muito controladas em sua família, mas, depois do casamento, e especialmente com o nascimento dos filhos, esse controle era quase inexistente. A família elitizada e secular de seu marido tinha uma concepção muito mais restrita dos espaços sociais em relação aos quais as mulheres poderiam circular. Annika Rabo argumenta que regras sobre interação entre homens e mulheres podem ser menos rigorosas nas áreas rurais (RABO, 2008, p. 134).

O pressuposto de que o principal desafio das mulheres no contexto de refúgio se relaciona à sua própria cultura informa o discurso de Joana, apresentado acima. Os discursos de Joana e de Maria, por sua vez, reproduzem visões sobre a "cultura" de mulheres muçulmanas e árabes, questionadas em Orientalismo (SAID, 1978). Tais visões produzem e informam pensamentos binários como Oriente versus Ocidente e bárbaro versus civilizado, e ocultam interesses econômicos e políticos bastante específicos. A maneira como, no mundo pós-colonial, "as mulheres se tornaram símbolos poderosos de identidade e visões da sociedade e da nação" (ABU-LUGHOD, 1996, p. 3) foi amplamente problematizada na antropologia. $\mathrm{O}$ uso do véu tem uma centralidade nessas visões. Em geral, os argumentos se apresentam sob o prisma da liberdade, como a ideia de que o uso significa uma libertação da 
hegemonia dos códigos culturais ocidentais ou uma forma de se opor ao estado secular opressor que promove, como no caso Sírio, um feminismo de estado. Saba Mahmood (2005) oferece uma perspectiva notadamente diferente para se pensar o uso do véu.

A etnografia de Mahmood nas mesquitas do Cairo, em um movimento conservador de mulheres, mostrou a força de uma nova concepção de agência, uma agência devota que foge à dicotomia subordinação e resistência. Mahmood defende uma separação entre a noção de agência e a de resistência como um passo fundamental para se pensar as formas de vontade e política que não se adequam às normas seculares e liberais feministas. "Quando o conceito de agencia se desligar do tropo da resistencia é que se poderão desenvolver questões analíticas que são cruciais para o entendimento dos projetos não liberais, sujeitos e vontades cuja lógica excede a enteléquia das políticas liberatórias" (MAHMOOD, 2005, p. 14). A perspectiva de Mahmood amplia a capacidade para compreender e interrogar as mulheres cujo sentido de self, aspirações, projetos e desejos, incluindo o de submissão a uma autoridade reconhecida, foram configurados no seio de tradições não liberais.

O uso do véu para Samia e outras interlocutoras não pode ser compreendido, tal como no discurso da trabalhadora humanitária, como expressão da imposição de seu marido e família tradicional. Essa visão da mulher muçulmana e árabe como passiva e submissa, presa às estruturas da autoridade masculina, já foi amplamente questionada (MAHMOOD, 2005, p. 6). Não considero igualmente adequado pensar o véu sob o prisma da liberdade de escolha ou como uma resposta ao processo de secularização do estado sírio (RABO, 1996, p. 167). A perspectiva de Mahmood é construída a partir de questionamentos teóricos, mas sobretudo a partir de práticas cotidianas de mulheres religiosas conservadoras, que não estavam tentando escapar da tradição ou mesmo reformar a concepção religiosa de gênero.

Mahmood valoriza o ponto de vista de suas interlocutoras, para as quais o uso do véu (assim como para Samia) é um exercício de 
modéstia e timidez (al-haya), uma das virtudes religiosas para os muçulmanos devotos em geral, e para as mulheres em particular. Para Samia, o uso do véu, assim como a adoção de um vestuário mais islâmico e a regularidade da oração (salat), relacionam-se a um processo disciplinador para a composição de um self virtuoso. Considerando a influência da concepção aristotélica de habitus no pensamento islâmico, em, por exemplo, Abu Hamid al-Ghazali (1058-1111) e Ibn Khaldun (1332-1406), Mahmood descreve como o habitus se refere a um esforço consciente para a reorientação da vontade, motivada pela concordancia entre motivaç̃óes internas, aç̃ôes externas e estados emocionais através da prática repetida de atos virtuosos. Mahmood concebe o véu como uma prática disciplinar que constitui subjetividades devotas, reconhecendo a agência de mulheres cuja ação é voltada para a construção de um habitus virtuoso.

\section{Considerações finais}

Este artigo dialoga e contribui para a literatura que busca romper com uma narrativa homogênea sobre os refugiados como corpos que precisam ser salvos, problematizando certos discursos humanitários. O texto também oferece uma contribuição de caráter etnográfico à produção acadêmica sobre refugiados do conflito sírio, desafiando a imagem visual das mulheres refugiadas como eternamente vulneráveis ou oprimidas por sua "cultura tradicional". O texto mostra que ao tratar as mulheres como um todo unificado, sem referência a classe, educação, devoção ou outros fatores relevantes, os discursos humanitários reproduzem estereótipos que reduzem a complexidade da experiência do refúgio a um "problema cultural".

Em contraste, o artigo buscou confrontar explicações de cunho culturalista, considerando o contexto social e político sírio, a classe social das mulheres, seus desejos e distintos projetos de modernidade. A perspectiva de Saba Mahmood (2005) tem um papel importante nesta análise, porque o seu conceito de agência é construído a partir de 
mulheres que não se conformam a projetos liberais e seculares. Mahmood problematiza o desejo universal de ser livre, situando a agência não somente em termos de resistência, mas como capacidades para ação alimentadas por relações concretas e específicas de subordinação.

\section{Referências}

ABU-LUGHOD, Lila. Remaking women. Feminism and Modernity in the Middle East. Princeton: Princeton University Press, 1996.

ACNUR. Global Trends, Forced Displacement in 2018. 2018. Disponível em: https:/ / www.unhcr.org/5d08d7ee.pdf.

ADLER-NISSEN, Rebecca; ANDERSEN, Katrine; LENE, Hansen. Images, emotions, and international politics: the death of Alan Kurdi. Review of International Studies, v. 10, p. 1-21, 2019.

AGIER, Michel. Managing the Undesirables: Refugee Camps and Humanitarian Government. David Fernbach, Cambridge, UK: Polity, 2011.

CHAGAS, Gisele Fonseca. Sufismo, carisma e moralidade: uma etnografia do ramo feminino da tariqa Naqshbandiyya-Kuftariyya em Damasco, Síria. Tese (Doutorado) - Universidade Federal Fluminense, 2011.

CHAMIE, Mary. Labour Force Participation of Lebanese Women. In: NASR, Julinda Abu; KHOURY, Nabil F.; ASSAM, Henry T. (Org.) Women, Employment, and Development in the Arab World. Berlin: Mouton, 1985.

COLSON, Elizabeth. Imposing Aid: The Ethnography of Displacement and its Aftermath. Kroeber Anthropological Society, v. 100, n. 1, p. 154167, 2011.

CONARE. Refúgio em números. 4. ed. 2019. Disponível em: https://www.acnur.org/portugues/wpcontent/uploads/2019/07/Refugio-emnu\%CC\%81meros_versa\%CC\%83o-23-de-julho-002.pdf. 
FASSIN, Didier. Didier Fassin. Entrevistado por Débora Diniz, Rio de Janeiro: EdUERJ, 2016.

FASSIN, Didier. La Raison Humanitaire: une histoire morale du temps présent. Hautes études, Paris, Éditions de l'EHESS (avec Le Seuil/Gallimard), 2010.

HAMID, Sonia C. (Des) Integrando Refugiados: Os Processos do Reassentamento de Palestinos no Brasil. 2012. 326 f. Tese (Doutorado) - Universidade de Brasília, Brasília. 2012.

HAMID, Sonia C. "Integrando" refugiados: discursos e práticas de gênero na gestão de palestinos no Brasil. In: NAVIA; HAMID; MUNEM; GOMES (Org.) Pessoas em movimento: práticas de gestão, categorias de direito e agências. Rio de Janeiro: FCRB/7Letras, 2019.

HARRELL-BOND, Barbara. Can humanitarian work with refugees be humane? Human Rights Quarterly, v. 24, n. 1, p. 51-85, 2002.

HARRELL-BOND, Barbara. Imposing Aid: Emergency Assistance for Refugees. Oxford University Press, 1986.

HERZFELD, Michael. The Social Production of Indifference: Exploring the Symbolic Roots of Western Bureaucracy. Chicago: University of Chicago Press, 1992.

HIJAB, Nadia. Women and work in the Arab world. In: JOSEPH, Suad; SLYOMOVICS, Susan. Women and power in the Middle East. Philadelphia: Library of Congress, 2001.

HIJAB, Nadia. Womanpower: The Arab Debate on Women at Work. Cambridge: Cambridge University Press, 1988.

JOSEPH, Suad. Brother/sister relationships: Connectivity, love, and power in the reproduction of patriarchy in Lebanon. American Ethnologist, v. 21, n. 1, p. 50-73, 1994.

KANDIYOTI, Deniz. Women, Islam and the State. Basingstoke: Macmillan, 1991.

LOKOT, Michelle. Blood doesn't become water'? Syrian Social Relations during Displacement. Journal of Refugee Studies, p. 1-22, 2018.

MAHMOOD, Saba. Politics of Piety: The Islamic Revival and the Feminist Subject. New Jersey: Princeton University Press, 2005. 
MALKKI, Liisa. Refugees and Exile: From 'Refugee Studies' to the National Order of Things. Annual Review of Antropology, v. 24, p. 495523, 1995.

MANFRINATO, Helena Morais. Dos quadros de guerra à participação: notas sobre a jornada do refúgio. Cadernos de Campo, São Paulo, v. 25, p. 421-436, 1991.

PINTO, Paulo G. Hilu. The Shattered Nation: The Sectarianization of the Syrian Conflict. In: HASHEMI, N.; POSTEL, D. Sectarianization: Mapping the New Politics of the Middle East. London: Hurst \& Company, 2017. p. 123-142.

QUATAERT, Donald. Ottoman Women, households, and textile manufacturing 1800-1914. In: KEDDIE, Nikki R.; BARON, Beth. Women in Middle Eastern History. Shifting Boundaries in sex and gender. New Haven: Yale University Press, 1991.

RABO, Annika. Doing Family: Two cases in contemporary Syria. Hawwa, v. 6, n. 2, p. 129-153, 2008.

RABO, Annika. Gender, State and Civil Society in Jordan and Syria. In: HANN, C.; DUN, E (Org.). Civil Society: Challenging Western Models. London: Routledge Ltd, 1996. p. 155-177.

SALAMANDRA, Christa. Chastity Capital: Hierarchy and Distinction in Damascus. In: KHALAF, S.; GAGNON, J. (Org.). Sexuality in the Arab World. London: Saqi Books, 2006. p. 152-162.

SALAMANDRA, Christa. A New Old Damascus: Authenticity and Distinction in Urban Syria. Bloomington: Indiana University Press, 2004.

SCHIOCCHET, Leonardo. Integration and Encounter in Humanitarian Tutelage. In: KOHLBACHER, Josef; SCHIOCCHET, Leonardo (Org.). From Destination to Integration - Afghan, Syrian And Iraqi Refugees in Vienna. Vienna: Austrian Academy of Sciences Press, 2017. 